\title{
Antalya'da yetiştirilen holstein sığırlarında kompleks vertebral malformasyon kalıtsal hastalığının allele özgü PCR ile belirlenmesi
}

\author{
Detection of complex vertebral malformation in holstein cattle reared in Antalya \\ using allele-spesific PCR
}

\author{
Murat Gökçe EREN(i), Murat Soner BALCIOĞLU(i), Eymen DEMİR \\ Akdeniz Üniversitesi, Ziraat Fakültesi, Zootekni Bölümü, 07070, Antalya \\ Sorumlu yazar (Corresponding author): M. S. Balcığlu, e-posta (e-mail): msoner@akdeniz.edu.tr \\ Yazar(lar) e-posta (Authore-mail): neretarum@gmail.com, eymendemir@akdeniz.edu.tr
}

\section{MAKALE BİLGİSİ}

Alınış tarihi 14 Haziran 2019

Düzeltilme tarihi 20 Ağustos 2019

Kabul tarihi 20 Ağustos 2019

\section{Anahtar Kelimeler:}

CVM

SLC35A3 geni

Kalıtsal hastalıklar

\section{ÖZ}

Bu çalışmada kalıtsal bir hastalık olan kompleks vertebral malformasyonun (CVM) Antalya ilinde yetiştiriciliği yapılan Siyah Alaca sığırlarında varlığı allele özgü polimeraz zincir reaksiyonu (AS-PCR) kullanılarak araştırılmıştır. Antalya Damızlık Sığır Yetiştiricileri Birliğine üye işletmelerden ve aynı birliğe üye olan Akdeniz Üniversitesi, Ziraat Fakültesi süt sığırcılığı işletmesine ait toplam 200 bireyde CVM kalıtsal hastalığının varlığı araştırılmıştır. Holstein sığırlarından elde edilen kan örneklerinden total genomik DNA izole edilmiştir. Sığır genomunun 3. kromozomu üzerinde bulunan SLC35A3 geninin 395 bç uzunluğundaki bölgesinde normal ve mutant allellerin belirlenmesinde farklı primerler kullanılmıştır. ASPCR işleminden sonra uygulanan agaroz jel elektroforezi sonuçlarına göre bireyler genotiplendirilmiştir. Bu çalışmada; incelenen 200 bireyden 7 tanesinin CVM taşıyıcısı olduğu belirlenmiştir.

\section{ARTICLE INFO}

Received 14 June 2019

Received in revised form 20 August 2019 Accepted 20 August 2019

\section{Keywords:}

CVM

SLC35A3 gene

Hereditary diseases

\begin{abstract}
This study aimed to analyze complex vertebral malformation (CVM) genetic defect in Holstein raised in Antalya province using allele specific PCR (AS-PCR). The presence of CVM mutant allele was investigated in 200 Holstein cows raised by member breeders of Antalya Cattle Breeders Association and raised in Akdeniz University, Faculty of Agriculture. Total genomic DNA was extracted from blood samples obtained from Holstein cows. In the 395 bp length of SLC35A3 gene region of bovine chromosome 3, different primers were used to identify the normal and mutant allele. By using agarose gel electrophoresis, individuals were genotyped after AS-PCR. In this study, 7 of 200 individuals were found as CVM carriers.
\end{abstract}

\section{Giriş}

2019 yılı itibariyle 7.5 milyar olan dünya nüfusunun gelecek yıllarda artacağ 1 tahmin edilmektedir (UNITED NATIONS 2019). Nüfus artışının, doğrudan tarımsal ürünlere olan talebin de artmasına neden olacağı bir gerçektir. Talebi karşılamak için tarımsal ürünlerde ıslah çalışmaları hız kazanmıştır. Islah çalışmaları sayesinde birim hayvandan daha fazla verim sağlanmıştır. Tarımsal ürünler içerisinde hayvansal ürünlerin önemi büyük olup; sığırlardan elde edilen süt ve et, toplumun beslenmesi için gereklidir. Sığırlar, insanlar tarafından doğrudan yenilmeyen kaba yemleri değerlendirip hayvansal proteine dönüştürebilirler. Birim alanda sığırlardan elde edilen süt ve et miktarı diğer çiftlik hayvanlarından daha yüksektir. Sı ğır yetiştiriciliğinde amaç kârlı bir üretim yapmaktır. Kârlı üretimin yapılabilmesi; başta sağlıklı damızlı hayvanların kullanılmasına bağlıdır. Hastalıkların bulunduğu işletmelerde üretim sekteye uğramakta ve yapılan üretim kârlılığını kaybetmektedir. Sığırlarda görülen BLAD (Bovine leukocyte adhesion deficiency; Sı̆̆ır lökosit bağlanma yetmezliği), DUMPS (Deficiency of uridine monophoshate synthase; Üridin monofosfat sentetaz eksikliği), FXID (Factor XI deficiency; Faktör XI eksikliği) ve CVM gibi hastalıklar doğrudan genetik yapıyla ilişkilidir (Kociba ve ark. 1969; Robinson ve ark. 1984; Shuster ve ark. 1992; Agerholm ve ark. 2001). Kalitsal hastalıklar sığırlarda fiziksel veya fonksiyonel bozukluklara neden olmakta ve verim özelliklerini olumsuz yönde etkilemektedir. 
CVM; Siyah Alaca sığırlarında görülen otozomal resesif olan kalıtsal bir hastalıktır. SLC35A3 geninin 559. nükleotitinde guaninin timine dönüşmesine neden olan nokta mutasyonu sonucunda hastalık görülmektedir (Gabor ve ark. 2012; Thomsen ve ark. 2006). İlk kez Danimarka'da varlığı bildirilen (Agerholm ve ark. 2001) CVM ölü doğumlara ve yavru atımına neden olmaktadır. Erken doğan buzağılarda; gelişmemiş bacaklar, kaburga sayısının eksikliği, boyun kısalığı, düşük vücut ağırlığı ve omurlarda yapışma gibi anomalilerin görüldügü bildirilmiştir (Duncan ve ark. 2001; Agerholm ve ark. 2004; Thomsen ve ark. 2006). CVM kalıtsal hastalığ1 resesif etkiye sahip olduğundan hasta bireyler rahatlıkla fenotipinden tanınıp sürüden çıkarılabilmektedir. Ancak taşıyıcı bireyler herhangi bir hastalık belirtisi göstermemektedir. Dolayısıyla hastalığa neden olan mutant allel, heterozigot bireylerin varlığı nedeniyle sürüde varlığını koruyabilmektedir. Taşıyıcı bireylerin belirlenip sürüden çıkarılmasıyla ekonomik kayıpların önüne geçilebilmektedir.

Gelişen moleküler teknikler sayesinde CVM taşıyıcısı olan bireyler doğumdan önce veya sonra belirlenebilmektedir (Agerholm ve ark. 2004). Tek nükleotit değişiminden kaynaklanan mutasyonların belirlenmesinde en çok kullanılan yöntem PCR-RFLP tekniğidir. Mutasyon bölgesini tanıyan restriksiyon enzimlerinin varlığında mutant ve normal bireyler bu yöntemle birbirinden ayırt edilebilmektedir.

CVM kalıtsal hastalığının belirlenmesinde günümüze kadar PCR-RFLP (Adamov ve ark. 2014; Citek ve ark. 2006), PCRSSCP (Chu ve ark. 2008; Rusc ve ark. 2013), CRS-PCR, PCRPIRA (Avanus ve Altınel 2017a), AS-PCR (Kanae ve ark. 2005), real-time PCR (Zhang ve ark. 2012), sekans analizi (Meydan ve ark. 2010), yüksek çözünürlüklü erime analizi (Gabor ve ark. 2012) yöntemi kullanılmasına rağmen en hızlı yöntemin AS-PCR olduğu bildirilmiştir (Avanus ve Altınel 2017a).

Bu çalışmada; AS-PCR yöntemiyle Antalya ilinde yetiştirilen Siyah Alaca sığırlarında CVM kalıtsal hastalığının varlığı araştırılmıştır. Hastalığın varlığının belirlenmesinin gerekli önlemlerin alınmasına yardımcı olacă̆ düşünülmektedir.

\section{Materyal ve Yöntem}

\subsection{Hayvan materyali}

Bu çalışmanın hayvan materyalini Antalya Damızlık Sığır Yetiştiricileri Birliğine üye olan yetiştiriciler tarafından yetiştirilen ve aynı birliğe üye olan Akdeniz Üniversitesi Ziraat Fakültesi Süt Sığırcılığı İşletmesinde yetiştirilen 200 adet sığır oluşturmaktadır.

\subsection{Kan örneklerinin alınması}

Kan örnekleri hayvanların boyun toplardamarından (Vena jugularis) alınmış ve EDTA içeren tüplere aktarılmıştır. Kan örnekleri soğuk zincir altında Akdeniz Üniversitesi, Ziraat Fakültesi, Zootekni Bölümü Genetik laboratuvarına ulaştırılmış ve DNA izolasyonu yapılıncaya kadar $-20^{\circ} \mathrm{C}$ 'de muhafaza edilmiştir.

\subsection{DNA izolasyonu ve miktarınin hesaplanmast}

Miller ve ark. (1988) tarafindan bildirilen DNA izolasyon protokolü uygulanarak kan örneklerinden toplam genomik DNA izole edilmiştir. DNA örneklerinin başarılı bir şekilde izole edildiğini belirlemek için agaroz jel elektroforezi kullanılmıştır. İzole edilen DNA örneklerinin miktarının belirlenmesinde spektrofotometre kullanılmıştır. Elde edilen DNA miktarları

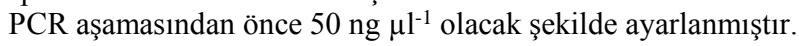

\subsection{PCR aşaması}

CVM kalıtsal hastalığı için normal ve taşıyıcı bireylerin belirlenmesinde Ghanem ve ark. (2008) tarafindan bildirilen primerler kullanılmıştır (Çizelge 1). SLC35A3 geninin 395 bç uzunluğundaki bölgesinin çoğaltılmasında kullanılan PCR reaksiyonu ve koşulları Çizelge 2-3'te gösterilmiştir.

Çizelge 1. Normal ve CVM allellerin belirlenmesinde kullanılan primerler.

Table 1. Used primers to detection of normal and CVM alleles.

\begin{tabular}{lc}
\hline \multicolumn{1}{c}{ Primer } & \multicolumn{1}{c}{ Primer Sekansı } \\
\hline $\begin{array}{l}\text { Normal allel } \\
\text { primeri }\end{array}$ & 5'-CACAATTTGTAGGTCTCATGGCAG -3 \\
$\begin{array}{l}\text { CVM alleli } \\
\text { primeri }\end{array}$ & 5'-CACAATTTGTAGGTCTCATGGCAT-3 \\
$\begin{array}{l}\text { Ortak reverse } \\
\text { primer }\end{array}$ & 5 ' GTTATACTACAGGAGTCACCTCT-3 \\
\hline
\end{tabular}

Çizelge 2. PCR reaksiyonu.

Table 2. PCR reaction.

\begin{tabular}{|c|c|}
\hline PCR Bileşenleri & Miktar \\
\hline $\mathrm{H}_{2} \mathrm{O}$ & $29.45 \mu 1$ \\
\hline $\mathrm{MgCl}_{2}$ & $4 \mu 1$ \\
\hline 10X Buffer & $4 \mu l$ \\
\hline dNTPS & $2 \mathrm{mM}$ \\
\hline Forward Primer & $20 \mathrm{pmol} \mu \mathrm{l}^{-1}$ \\
\hline Reverse Primer & $20 \mathrm{pmol} \mu \mathrm{l}^{-1}$ \\
\hline Taq DNA Polimeraz & $5 \mathrm{U} \mu \mathrm{l}^{-1}$ \\
\hline Total DNA & $50 \mathrm{ng} \mu \mathrm{l}^{-1}$ \\
\hline
\end{tabular}

Çizelge 3. PCR koşulları.

Table 3. PCR conditions.

\begin{tabular}{lccc}
\hline \multicolumn{1}{c}{ Așama } & Süre & Sıcaklık & Döngü Sayısı \\
\hline Ön Denatürasyon & $2 \mathrm{dk}$ & $95^{\circ} \mathrm{C}$ & 1 \\
Denatürasyon & $30 \mathrm{sn}$ & $95^{\circ} \mathrm{C}$ & \\
Bağlanma & $30 \mathrm{sn}$ & $62^{\circ} \mathrm{C}$ & 30 \\
Uzama & $30 \mathrm{sn}$ & $72^{\circ} \mathrm{C}$ & \\
Son Uzama & $10 \mathrm{dk}$ & $72^{\circ} \mathrm{C}$ & 1 \\
\hline
\end{tabular}

\section{Bulgular ve Tartışma}

Bu çalışmada DNA izolasyonu ve PCR aşaması başarılı bir şekilde gerçekleştirilmiştir. PCR ürünlerinin görüntülenmesinde hem normal hem de mutant alleli çoğaltan primerler kullanılmış ve aynı bireye ait her iki allelin varlığ agaroz jel üzerinde gösterilmiştir. Normal allelleri taşıyan bireylerde 395 baz çifti uzunluğunda tek bant görülürken taşıyıcı bireylerde aynı uzunlukta iki bant (normal ve mutant) görülmüş̧ür. Taşıyıcı olan bir bireye ait örnek Şekil 1'de yuvarlak içine alınmıştır.

Antalya ilinde yetiştirilen Siyah Alaca sı̆̆ır ırkına ait 200 bireyde CVM kalıtsal hastalığının araştırıldığ 1 çalışmada 7 adet CVM taşıyıcısının varlı̆̆ saptanmıştır. Taşıyıcı hayvanların oran $1 \% 3.5$ olarak belirlenmiştir.

Mevcut çalışmadan elde edilen sonuçlar Türkiye'de yetiştiriciliği yapılan Siyah Alacalarda yapılan çalışmaların 


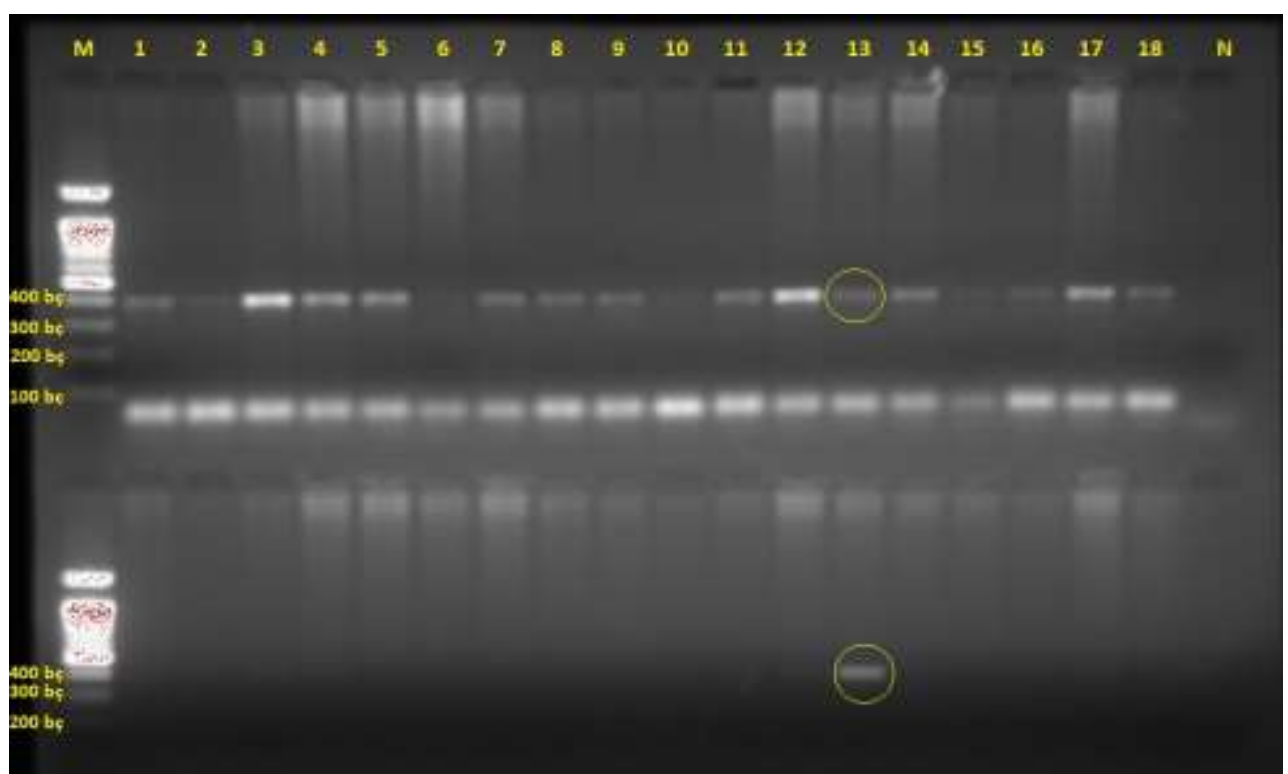

Şekil 1. 395 bç uzunluğundaki CVM genotiplerinin agaroz jeldeki görüntüsü (M: 100 bç marker, N: Negatif kontrol, 1-18: AS-PCR ürünleri; 13. Sıra: CVM taşıyıcısı birey).

Figure 1. Image of 395 bp length CVM genotypes on agarose gel (M: 100 bp DNA ladder, N: Negative control, 1-18: AS-PCR products, Lane 13: CVM carrier.

sonuçları ile benzer bulunmuştur. Meydan ve ark. (2010) 350 Siyah Alaca örneği ile yaptığı çalışmada taşıyıcı bireylerin oranının \%3.4, Avanus ve Altınel (2017b) ise Trakya'da yetiştirilen 90 Siyah Alaca örneklerinde taşıyıcı bireylerin oranının \%3.2 olduğunu bildirmiştir. Diğer ülkeler ile kıyaslandığında Türkiye'de yetiştirilen Siyah Alaca sığır popülasyonunda CVM hastalığının varlığı daha düşük bulunmuştur. CVM hastalığının Danimarka'da \%31 (Agerholm ve ark. 2004), Polonya'da \%24.8 (Rusc ve Kaminski 2007), Japonya'da \%32.5 (Nagahata ve ark. 2002), Çek Cumhuriyeti'nde \%18.9 (Citek ve ark. 2006), İsveç’te ise \%23 (Berglund ve ark. 2004) oranında görüldüğü bildirilmiştir.

Söz konusu ülkelerde CVM hastalığının sık görülmesinin nedeni yapay tohumlamada kullanılan spermaların CVM taşıyıcısı olduğu bilinen Carlin-M Ivanhoe isimli boğa ile akraba olan boğalara ait olmasından kaynaklandığı bildirilmiştir (Agerholm ve ark. 2004).

Mevcut çalışmada tespit edilen CVM taşıyıcı bireylerin oranı Makedonya'da \%1.1 (Adamov ve ark. 2014), Almanya'da \%2.3 (Schütz ve ark. 2008), Çin'de \%2.9 (Wang ve ark. 2011) yapılan çalışmalarda bildirilen değerlerden yüksek bulunmuştur. İran'da yetiştirilen Siyah Alaca sığırlarında ise CVM taşıyıcısı bireylere rastlanmamıştır (Rezaee ve ark. 2008; Hemati ve ark. 2015).

Bu çalışmada; Siyah Alaca sığırlarında CVM hastalığının belirlenmesinde AS-PCR yöntemi kullanılmıștır. Tek PCR ve elektroforez aşamasını içeren AS-PCR zamandan kazanç sağladığından birim zamanda daha fazla örnekle çalışılmasına olanak tanımaktadır.

\section{Sonuç}

Islah çalışmaları sayesinde istenen özellikler yavrulara aktarıldığı gibi fenotipik olarak saptanamayan kalıtsal hastalıklara neden olan mutant alleller de yavrulara aktarılabilmektedir. Islah çalışmalarını hızlandırdığı için yapay tohumlama sıklıkla kullanılan bir yöntemdir. $\mathrm{Bu}$ yöntem sayesinde bir boğadan birden fazla yetiştirici yararlanabilmektedir. Yapay tohumlamada kullanılan boğaların CVM gibi kalıtsal hastalıkların taşıyıcısı olması durumunda hastalığın bulunmadığı sürülerde bile hastalık ortaya çıkabilmektedir. Kalıtsal hastalıkların önüne geçmek ve işletmelerde ekonomik verim seviyesini korumak için aday boğaların bilinen bütün kalıtsal hastalıklar bakımından test edilmesi gereklidir. İşletmeye alınacak damızlık bireylerin veya yapay tohumlamada kullanılan spermaların ait olduğu bireylerin kalıtsal hastalıkları taşıyıp taşımadığının belirlenmesi önem arz etmektedir.

\section{Teşekkür}

$\mathrm{Bu}$ çalışma Akdeniz Üniversitesi Bilimsel Araştırma Projeleri Koordinasyon Birimi tarafindan 2014.02.0121.016 nolu proje ile desteklenmiştir.

\section{Kaynaklar}

Adamov N, Mitrov D, Esmerov I, Dovc P (2014) Detection of recessive mutations (BLAD and CVM) in Holstein-Friesian cattle population in Republic of Macedonia, Macedonian Veterinary Review 37: 6168.

Agerholm JS, Bendixen C, Andersen O, Arnbjerg J (2001) Complex vertebral malformation in Holstein calves, Journal of Veterinary Diagnostic Investigation 16: 283-289.

Agerholm JS, Bendixen C, Arnbjerg J, Andersen O (2004) Morphological variation of 'complex vertebral malformation' in Holstein calves Journal of Veterinary Diagnostic Investigation 16: 548-553.

Avanus K, Altınel A (2017a) Comparison of allele-spesific PCR, created restriction-site PCR, and PCR with primer-introduced restriction analysis methods used for screening complex vertebral malformation carriers in Holstein cattle. Journal of Veterinary Science 18: 465-470.

Avanus K, Altınel A (2017b) Inherited diseases of Holstein cattle: Stroy so far in Turkey. Journal of Istanbul Veterinary Sciences 1: 40-46.

Berglund B, Persson A, Stalhammar H (2004) Effects of complex 
vertebral malformation on fertility in Swedish Holstein cattle. Acta Veterinaria Scandinavica 45: 161- 165.

Chu Q, Sun D, Yu Y, Zhang Y, Zhang Y (2008) Identification of complex vertebral malformation carriers in Chinese Holstein. Journal of Veterinary Diagnostic Investigation 20: 228-230.

Citek J, Rehout V, Hajkova J, Pavkova J (2006) Monitoring of the genetic health of cattle in the Czech Republic. Veterinarni Medicina 51: 333-339.

Duncan RB, Jr, Carrig CB, Agerholm JS, Bendexian C (2001) Complex vertebral malformation in a Holstein calf: Report of a case in the USA. Journal of Veterinary Diagnostic Investigation 13: 283-289.

Gabor M, Miluchova M, Trakovicka A, Riecka Z, Candrak J, Vavrisinova K (2012) Detection of complex vertebral malformation carriers in Slovak Haolstein cattle by high resolution melting analysis. Acta Veterinaria 62: 239-248.

Ghanem ME, Akita M, Suzuki T, Kasuga A, Nishibori M (2008) Complex vertebral malformation in Holstein cows in Japan and its inheritance to crossbred F1 generation. Animal Reproduction Science 103: 348-354.

Hemati B, Gharaie-Fathabad S, Fazeli MH, Namvar Z, Ranji M (2015) Investigation of bovine leukocyte adhesion deficiency (BLAD) and complex vertebral malformation (CVM) in apopulation of Iranian Holstein cows. Iranian Journal of Apllied Animal Science 5: 69-72.

Kanae Y, Endoh D, Nagahata H, Hayashi M (2005) A method for detection complex vertebral vertebral malformation in Holstein calves using polymerase chain reaction-primer introduced restriction analysis. Journal of Veterinary Diagnostic Investigation 17: $258-262$

Kociba GD, Ratnoff OD, Loeb WF, Wall RL, Heider LE (1969) Bovine thromboplastin antecedent (factor XI) deficiency. Journal of Laboratory and Clinical Medicine 74: 37-41.

Meydan H, Yildiz MA, Agerholm JS (2010) Screening for bovine leukocyte adhesion deficiency, deficiency of uridine monophoshate synthase, complex vertebral malformation, bovine citrullinaemia, and factor XI deficiency in Holstein cows reared in Turkey. Acta Veterinaria Scandinavica 52: 56.

Miller S, Dykes D, Plesky HA (1988) Simple Salting out Procedure for Extracting DNA from Human Cells. Nucleic Acids Research 16: 1215.

Nagahata $H$, Oota $H$, Nitanai A, Oikawa S, Higuchi $H$, Nakade T, Kurosawa T, Morita M, Ogawa H (2002) Complex vertebral malformation in a stillborn Holstein calf in Japan. Journal of Veterinary Medical Science 64: 1107-1112.

UNITED NATIONS (2019) World population 2019: World chart https://population.un.org/wpp/DataQuery/. Accessed 1 June 2019.

Rezaee AR, Nassiry MR, Valizadeh R, Tahmoorespour M, Javadmanesh A, Zarei A, Janati H (2008) Study of complex vertebral malformation disorder in Iranian Holstein Bulls. World Journal of Zoology 3: 36-39.

Robinson JL, Dombrowski DB, Harpestad GW, Shanks RD (1984) Detection and prevalance of UMP synthase deficiency among dairy cattle. Journal of Heredity 75: 277-280.

Rusc A, Kaminski S (2007) Prevalence ofcomplex vertebral malformation carriersamong Polish Holstein-Friesian bulls. Journal of Applied Genetics 48: 247-252.

Rusc A, Hering D, Puckowska P, Barcewicz M, Kaminski S (2013) Screening of Polish Holstein-Friesian bulls towards eradication of complex vertebral malformation (CVM) carriers. Polish Journal of Veterinary Sciences 16: 579-581.

Schütz E, Scharfenstein M, Brenig B (2008) Implication of complex vertebral malformation and bovine leukocyteadhesion deficiency DNA-based testing on disease frequency in the Holstein population. Journal of Dairy Science 91: 4854-4859.

Shuster DE, Kehrli ME, Ackermann MR, Gilbert RO (1992) Identification and prevalance of a genetic defect that causes leukocyte adhesion deficiency in Holstein cattle. Proceedings of the National Academy of Sciences of the United States of America 89: 9225-9229.

Wang C, Tong Q, Hu XZ, Yang LG, Zhong XO, Yu Y, Wu JJ, Liu WJ, Li X, Hua GH, Zhao HQ, Zhang SJ (2011) Identification of complex vertebral malformation carriers in Holstein cattle in South China. Genetics and Molecular Research 10: 2443-2448.

Thomsen B, Horn P, Panitz F, Bendixen E, Petersen A H, Holm, LE, Nielsen VH, Agerholm JS, Arnbjerg J, Bendixen C (2006) A missense mutation in the bovine SLC35A3 gene, encoding a UDPNacetylglucosamine transporter, causes complex vertebral malformation. Genome Reserch 16: 97-105.

Zhang Y, Fan X, Sun D, Wang Y, Yu Y, Xie Y, Zhang S, Zhang Y (2012) A novel method for rapid and reliable detection of complex vertebral malformation and bovine leukocyte adhesion deficiency in Holstein cattle. Journal of Animal Science and Biotechnology 3: 24 